\title{
INNOVATION IN THE PUBLIC SECTOR: BEYOND THE RHETORIC TO A GENUINE 'LEARNING CULTURE'
}

\author{
Andrew Podger \\ The Australian National University
}

There are several key points I want to highlight in this chapter. First, that the word innovation has become very fashionable - you see it in the names of organisations, departments and public service values, and so on - but we need to be careful when using the term. This is not to say it is unimportant or irrelevant, but that we need to clarify what innovation means, test the suggestions that are made to promote it in the public sector and be conscious that there are downsides and risks involved.

Second, and in the same context, it is also important to remember that stability is in fact a core public sector role. Textbook public finance literature (Musgrave and Musgrave 1980) identifies three functions of government, one of which is stability. This refers mainly to handling the economic cycle and managing the risks of inflation and unemployment, but it is also more generally about setting the legal and economic framework within which individuals and private organisations can go about their lives and businesses with confidence.

Innovation in the public sector has to take account of public sector factors. Various Australian Public Service (APS) agencies have issued guidelines in recent years on how to foster innovation. Some of them have useful suggestions; others are more mixed, and in many respects do not square with the reality public 
servants work within today. Actions speak louder than words, and quite a few recent developments have worked against, not towards, innovation. Innovation requires a culture of trust and learning rather than a culture of control, and yet the culture of control has been a hallmark of recent history.

For this reason I am going to propose two strategies: one is what I call 'back to basics' - things that we ought to do that we seem to have lost sight of recently. We need more time and resources for policy research, regular statistical work, and so on; we need technical expertise, not just generalist skills; we need more permission and devolution - things that have been harder to find in recent times; and we need to revisit the idea of learning organisations. If we get these basics right, we can apply them equally in times of austerity as we can in times of plenty, to help governments meet prevailing challenges.

In addition to some 'back to basics', I suggest we try some new approaches. In particular, I suggest we explore the ideas of Charles Sabel about 'experimentalist democracy' and 'pragmatic governance' (Sabel 2004). These ideas are not entirely foreign to Australia-we have successfully taken a pragmatic approach to many of our reforms over the last 30 years - but I want to suggest we explore how to pursue the approach more systematically.

\section{International interest in innovation in the public sector}

Innovation in the public sector has become a popular topic around the world. Interest seems to have started in the UK some years ago (the Improvement and Development Agency (IDeA) established by the Local Government Association (LGA) in 1998 (LGA 2014; NAO 2000; Mulgan and Albury 2003; DIUS 2008)), then crossed the Atlantic to the Harvard Kennedy School (Eggers and Shalabh 2009). The Organisation for Economic Cooperation Development (OECD) also became interested (Box 2009) and established its Observatory of Public Sector Innovation in 2010. In Australia, we have had a series of reports starting with Ahead of the Game (DPMC 2010 - Terry Moran's 2010 report on Australian government administration) promoting greater innovation in the APS, and an Australian National Audit Office (ANAO) guide (ANAO 2009), and an Australian Public Service Commission (APSC) Management Advisory Guide (MAC) guide (MAC 2010).

More recently, a few commentators have expressed caution. Wolfgang Drechsler was in Australia recently questioning aspects of the enthusiasm for innovation in the public sector (Drechsler 2012). He noted that the Schumpeter definition of innovation is fundamentally about the market - it is not simply about 
inventions, but is a phenomenon where a new product or service is successfully introduced and the innovator can exploit their short-term monopoly. That is what innovation in the economic literature refers to. But good public administration rarely, if ever, looks innovative in that sense. Yet it can-and has to-be supportive of Schumpeterian innovation. Understanding this matters, because some of the popular focus on innovation sounds like novelty for novelty's sake, and novelty for novelty's sake can be counterproductive in facilitating private sector innovation. ${ }^{1}$

As mentioned, another reason for caution is that stability is one of the three core functions of government in a market economy (along with allocation of resources and redistribution). The public sector sets the framework within which individuals and businesses can go about their lives and operate with confidence knowing society's rules. This provides an environment conducive to investment and innovation. So a degree of stability in government can actually enhance innovation in society.

None of this means that innovation is not important in the public sector: it is important and the popular interest in it is both understandable and appropriate.

\section{Drivers and challenges}

Some of the drivers for more innovation in the public sector are the same drivers behind new public management (NPM) 25 years ago. These include the need for agility and flexibility and the capacity to adjust to rapid change in societywhether it be from globalisation, technological change or something else. Efficiency in public administration is important - and it always will be. There is a need to improve our responsiveness to the needs and preferences of citizens, so we have to be able to adapt. Moreover, there are benefits from drawing on private sector experience, including risk management, strategic planning and performance measurement. This was the context for the new public management reforms and they are no less relevant today to the current interest in innovation.

Promoting innovation offers additional benefits beyond those of NPM (and its subsequent modifications and enhancements through network governance etc.). In particular, it looks to foster new ideas and to subject these to experimentation and practical evaluation. There is more emphasis on translating ideas into practice - so implementation receives more attention than it did in the early days of new public management. While it is consistent with continuous

1 Joseph Schumpeter argued that a fundamental force of capitalism is innovation and what he termed 'creative destruction' whereby entrepreneurs develop new products for which for some time they have a monopoly (Schumpeter 1942). 
improvement, it also promotes testing of more radical change. This is perhaps particularly relevant in times of austerity and crisis. Such times often permit more radical change as well as require it.

In promoting innovation, however, we also need to learn from some of the mistakes made in the NPM reforms. One of the lessons from our experience was that private sector practice is not always the most appropriate model for the public sector. The public sector context nearly always involves multiple objectives which are not always able to be clearly articulated. Yet in new public management we tried to set specific goals and targets; to use organisational and programmatic stovepipes and principal-agent frameworks which could be tightly managed or monitored, applying private sector practices. But we did not always take sufficient account of the complexity of political accountability, and the challenges of identifying the broader public interest. There were also, at times, issues about the ethical application of public power, because in our focus on results we sometimes understated the importance of means and processes in the public sector.

When considering innovation in the public sector, we need to think about the public sector factors that may be particularly important. One of them is the importance of engaging with politics. Innovation is not just a matter for technical experts or administrators; engagement with politics is essential to making any major innovation work. That engagement will almost certainly identify multiple and competing objectives, and it also offers a process to allow these to be tested and weighed up. The other key public sector factor concerns the role and values of public service: having impartial, professional, consistent and stable management, notwithstanding the need to be innovative. The challenge, as I once put it some years ago, is to promote innovation with integrity (Podger 2004).

\section{Australian guidelines for innovation}

The two main guides issued in Australia came from the ANAO in 2009 and the MAC (published by the APSC) in 2010. The ANAO guidelines discuss the preconditions for innovation and the processes to foster and shape innovation. Both give a lot of emphasis to what might be referred to as the ideal 'policy cycle view' of the world of decision-making - you make a decision, you implement it, you review it, you then look at the problems with it, you come up with a new set of suggestions and make a new decision and repeat the cycle. I will return to this approach shortly, as I am not sure it represents the real world or necessarily the most desirable way to promote useful innovation. 
The two sets of guidelines include many very sensible suggestions, particularly about the importance of organisational leadership (for example, fostering a permissive or empowering culture) and having a supportive corporate strategy. There is also quite a lot of emphasis on organisation capability: knowing your business, having the necessary information, having the right information flows and having capacity within the organisation to think outside the current paradigm. Moreover, the guidelines promote collaboration and external engagement, and rightly expound the importance of implementation.

But there seem to be several somewhat questionable elements. Firstly, the guidelines are presented rather like cookbooks - a list of things to do and to tick off-and I don't think that is the way innovation is ever going to work. There is also the suggestion that innovation is a core public sector value, when I would say firmly it is not. Public servants should be innovative, but innovation is not actually one of the core values that helps to define the public sector. It is a core value of the private sector, which must retain a competitive edge.

Most importantly, I contrast what is presented in these guidelines with what has actually been happening over the last five or six years. In that period - at least at the Commonwealth level, and I suspect in most of the states - there has been a reversal of devolution. There have been increased numbers of people at the top, fewer 'Indians', and a lot of authority down the line has been taken away. There has also been reduced tolerance of risk. The 'pink batts' story provides a telling illustration. What are the lessons so far taken from that? Essentially, they are: do not let such a thing ever happen again; put in place stronger central controls; have more senior managers. And yet, the pink batt story included some really innovative, clever ideas, such as the use of the vocational training sector, and the Centrelink processes for actually managing payments, which had never been thought about in the environmental field before. But the political and bureaucratic lessons in practice are exclusively about minimising risk - not managing risk and welcoming innovation. (This is not to suggest that risk was managed well-it evidently was not.)

We have also experienced ever-increasing political control of communications and policy debates. Consequently, departments are not engaging outside their organisations as much as they used to, and they are publishing less and speaking publicly less often. There are exceptions, but senior public servants are understandably cautious about being drawn into partisan public debates, particularly when they see colleagues get into political strife because of misrepresentations of what was said. But such caution is hardly conducive to the atmosphere and culture needed for innovation. There is also increasing emphasis on being able to answer a policy issue immediately-allowing no time to reflect, let alone to test different ideas and approaches. 'We need 
something now ... it's in the press today ... on the radio or in social media right now ... 24/7 ... the minister has got to respond to stop the speculation building further, so get the briefing with clear and firm points that are "on message" ....'

Even within Ahead of the Game, there is the disappointing suggestion that more mobility is necessarily a good thing. Well, mobility can be a good thing, but in many places much expertise has been lost in recent years and regaining it is now more important than increased mobility. Stability is also important to nurturing effective relationships with external stakeholders. Agencies need to balance mobility and stability, and generalist and specialist skills: innovation is often facilitated by bringing in different perspectives, but it also requires expert knowledge and deep ongoing partnerships, and there is often nothing more dangerous than generalists running off with what they think are clever ideas.

\section{Two complementary strategies}

This leads me to propose two strategies for promoting innovation in a way that is relevant to the public sector: 'back to basics' and exploring more systematically the 'experimentalist democracy' ideas from Charles Sabel.

The 'back to basics' strategy is about rebuilding our strategic policy capability. This was one of the priorities in Terry Moran's report Empowering Change: Fostering innovation in the Australian Public Service to the Department of Prime Minister and Cabinet 2010, one I strongly endorse. Steve Sedgwick (APSC 2013) and others have also referred to it publicly, including through the recent capability reviews. Associated with this is the need to reintroduce some learning organisation principles. This 'back to basics' strategy, however, is still within a framework that is policy-oriented and rather top-down. The experimentalist democracy idea is much more bottom-up and experiential. As such, it could usefully complement the first strategy.

\section{'Back to basics' strategy}

What would the 'back to basics' strategy involve? First, notwithstanding all the pressures on departmental budgets, we need to allocate resources to ongoing policy research and data analysis in every department. This would assist the ideal cycle of systematic policy development and informed decision-making that I referred to earlier. More importantly, it would assist in the rather different real world in which today's policy advisers live. Most of us know that the policy cycle is a normative way of looking at the world, but it is not actually how it works. In practice what happens is an event occurs and departments are pressed to give the minister immediate advice to respond to that event. So how 
do you make sure that advice is well informed? The key is for the department to have invested in ongoing policy research and development and in ongoing statistical data analysis, which can be drawn upon quickly as required. The dedicated resources involved need to be somewhat protected from the $24 / 7$ media cycle, but able to be promptly accessed. They also, in turn, need to have close links with external expertise, whether in universities or think tanks or the more skilled advocacy organisations. Getting the most from external expertise requires considerable internal expertise, and internal experts are often in a unique position to understand administrative data. I am also not sure the policy cycle is necessarily an ideal approach; getting the most from external experts often requires an iterative process leading to shared understanding often outside the context of current policy debates.

Which brings me to the importance of retaining and nurturing expertise and not overemphasising the role of the generalist: a key part of the 'back to basics' strategy is to ensure there is a balance between generalists and specialists.

We also need to think, once again, about devolved authority. Particularly under the Rudd and Gillard governments, too many matters went to cabinet (or, worse, to a small kitchen cabinet), and not enough was left to portfolio ministers and their ministerial teams. Within portfolios and agencies, the idea of flatter structures has largely been lost and with this the ability to push things down the line giving people more management authority including in relation to policy advice. Of course to do this you do need to have a framework of performance management and risk-based quality assurance controls.

This strategy includes a renewed focus on leadership that promotes a culture of learning (learning will also receive close attention in the second strategy). Doing this requires activities such as regular forums for discussion of both program experience and policy research. This may be harder than in the past because of the greater separation of policy from administration (for example, where service provision is contracted out or administered in a different agency or portfolio or by a different jurisdiction), but it is essential to innovation that works.

It also encompasses engagement with external expertise and external stakeholders. Australia (and New Zealand) have done a lot of good work in this space in recent years, but a lot more needs to be done. Amongst other aspects, access to the data that departments hold is still not nearly good enough to promote effective interchange and dialogue, and there remains considerable reluctance to engage fully with academic experts.

Peter Senge's 'Learning Organisation' ideas (Senge 1990) are now more than 20 years old, but many aspects are still highly relevant. Indeed, some of the more recent writings about innovation apply very similar concepts to Senge's 
five 'disciplines', including in particular 'systems thinking' - the need to consciously consider connections and interactions between programs and organisations when addressing significant problems. 'Personal mastery' is also important, involving both expertise in the organisation's core business and skills with working with people. 'Mental models' are relevant to the appreciation of different perspectives, understanding where people are coming from and recognising the assumptions being made that may never have been stated. 'Shared vision' and 'team learning' are also relevant, going beyond learning by each individual to group learning towards a shared objective. These principles of learning organisations need to be taken on board again as part of the 'back to basics' strategy, as they are particularly relevant in the press for innovation.

The reason why this 'back to basics' agenda is important is that we know from past history that when we did these things well, we saw a lot of good policy changes supported and initiated by the public service, including in times of austerity. A number of prominent Australian public policy practitioners were involved in these. I was involved in the 1976 family allowances reform: the new Fraser government wanted budgetary savings, Treasury proposed means-testing child endowment; a good cross-agency system of reviewing this proposal came up with the alternative of family allowances - a much enhanced child endowment system that brought together tax rebates and welfare payments, a very different and innovative outcome compared to the one originally suggested. In 1983, the new Hawke government was looking for budgetary savings to redirect towards employment enhancing activities. One of many reforms that year was a total rethink of housing programs, replacing highly expensive tax assistance with enhanced support for public housing and other measures that both promoted employment and helped more needy people. First steps were also taken that year to remove distortions in our then very weak superannuation arrangements as part of a review of the retirement income system. The youth allowance reform was introduced over several years but it was in the context of the extremely tough 1987 budget that it was finally pushed through, realising savings in youth unemployment benefits in a package that aimed to promote continued education and training. It was also around this time that the original Higher Education Contributions Scheme (HECS) was introduced, involving not only the budgetary savings from requiring people to repay some university costs when their incomes later grew, but redirecting savings to greatly expand places, including for disadvantaged youth.

I raise each of these here as they are all areas ripe for further reform, now that we are in another period of austerity. The policy mechanisms and processes in those times were, I believe, factors in their success even if, undoubtedly, political leadership was the final essential ingredient. 


\section{Sabel's 'experimentalist democracy' strategy}

The second strategy I propose is taken from Charles Sabel's work on experimentalist democracy (Sabel 2004). His focus is primarily on where ends and means cannot be easily distinguished and where issues cross agency and jurisdictional boundaries - 'wicked problems'. He is concerned that a top-down approach using principal-agent mechanisms is often not appropriate in these cases and he suggests instead a bottom-up approach often using civil society actors who not only provide the services but have permission to both set many of the rules and to supervise themselves. This is nonetheless subject to public monitoring of that self-supervision and to the legislature setting and reviewing the broad policy intent.

Democratic accountability is firmly in place in this model, but it allows much more discretion than is currently the norm and relies on much more open, informed debate and review. It is directed as much to improving public political discourse as it is to improved public service management. Under the model, 'framework laws' would commit society to identified broad goals. The administrative infrastructure would help agents to set and revise standards in light of what they learn and from pooling their efforts to improve (typically these would include requirements for independent professional bodies to monitor performance and to disseminate lessons). Independent monitoring and evaluation in turn would contribute to regular reviews by parliament, including of the framework laws.

Sabel has written about a number of case studies in both Scandinavia and the US. The Finnish one is particularly interesting: it concerns special education for kids from particularly difficult backgrounds. The monitoring and evaluation process, and dissemination of lessons learned, was led by independent professional organisations, not the teachers' unions. His other case studies include food safety in the US and hospitals in Sweden.

There are limitations and risks associated with this model. The most obvious one relevant to Australia is whether Australian politicians or the media would ever allow this level of experimentation and discretion? This may suggest the model should first be explored in areas where there is more likely to be bipartisan agreement on the importance of the problem and of the uncertainty about the best policy response.

In these areas, there is still the challenge to articulate meaningful, broad society goals without detailed, specific objectives and program rules. For example, one of the problems we have seen in the Indigenous policy field has been the continued insistence at the top (whether it be the parliament, or the Council of Australian Governments) to set detailed measures of performance when perhaps 
what we really need is something broader which allows detailed measures and their objectives to be worked through at a more localised level subject to independent monitoring and dissemination of lessons learned.

A related challenge is to decide when this highly discretionary, bottomup approach would be more likely to maximise public value, than our more developed top-down performance management approach. Other contributors to this volume have identified the advantages of principal-agent and provider competition arrangements. This is not the model here - which is much more about collaboration and learning. Which policy areas are most suited to competition and which ones to collaboration and learning? There is no simple answer, but relevant factors might include the complexity of the policy issue and the extent to which the culture and values of the charitable sector and other key external stakeholders have proven to be important.

Other challenges include containing provider self-interests, establishing financial controls, balancing the desirability of discretion and experimentation with concerns for equitable entitlements to services and treatment, and ensuring ethical standards in the experiment methodology and practice.

There are a number of current initiatives which bear some resemblance to Sabel's ideas. The National Disability Insurance Scheme and its pilot studies provide one example. To a lesser extent, the work done recently to give hospital boards more autonomy and professional independence (but with high-level performance metrics) fits the model. Regional primary healthcare organisations, or Medicare Locals, have certainly been the subject of experimentation in recent years. And there is scope to return to the agenda explored some years ago through the coordinated care trials for chronically ill patients.

Perhaps the area most suited to the experimentalist approach, at least for the Commonwealth, is Indigenous welfare. If we were to pursue this more systematically, the following action might be considered:

- Establishing a joint parliamentary committee to agree society goals and oversee developments (assisted by the National Congress of Australian First Peoples).

- Allowing considerable bottom-up experimentation including reporting to (not by) local communities.

- Having a lead Indigenous agency that can coordinate across government for each community/experiment, with sufficient expertise and on-the-ground experience to maintain close relations with communities.

- Various professions, researchers and independent Indigenous organisations to ensure independent monitoring and sharing of lessons. 
A major state example would be child protection. The social benefit bonds initiative in New South Wales discussed in this book is a good example within this policy field. More generally, there may be scope for more carefully designed experimentation even involving randomised trials, within a framework that ensures findings are public and lessons disseminated. Other possibilities include prisons (perhaps drawing on New Zealand experience) and special education.

\section{Conclusion}

The current interest in innovation in the public sector runs the risk of being just another fad. We need to appreciate the public sector context and role.

This is not to deny the relevance and importance of innovation in the public sector but to promote a more nuanced understanding. If we are to promote innovation that contributes to public value, I suggest serious consideration be given to two strategies: the first is to return to some practices which seem to have been allowed to wither, and the second to explore a new approach that allows for more experimentation and learning from practice, particularly in complex policy areas.

\section{References}

Australian National Audit Office (ANAO). 2009. Innovation in the Public Sector: Enabling Performance, Driving New Directions Better Practice Guide. Canberra. Online: www.anao.gov.au/uploads/documents/Innovation_in \% 20 the_Public_Sector.pdf (accessed 19 May 2015).

Australian Public Service Commission (APSC). 2013. State of the Service Report 2012-13. Canberra. Online: apsc.gov.au/about-the-apsc/parliamentaryreports/state-of-the-service-series/state-of-the-service-2012-13.pdf (accessed 15 June 2015).

Box, Sarah. 2009. 'OECD work on innovation - a stocktaking of existing work.' Directorate for Science, Technology and Industry. STI Working Paper 2009/2. Paris. Online: www.oecd.org/sti/42095821.pdf (accessed 19 May 2015).

Department of Innovation, Universities and Skills (DIUS). 2008. Innovation Nation. March. Norwich: UK Government.

Department of Prime Minister and Cabinet (DPMC). 2010. Ahead of the Game; Blueprint for the Reform of Australian Government Administration. Report of the Advisory Group on Australian Government Administration. March, Canberra. 
Drechsler, Wolfgang. 2012. 'Is public sector innovation overrated?' Institute of Public Administration Australia 2012 International Congress, Melbourne, 18-20 September.

Eggers, William D. and Kumar Singh Shalabh (Deloitte Research). 2009. The Public Innovator's Playbook: Nurturing Bold Ideas in Government. Boston: Harvard Kennedy School, Ash Institute for Democratic Governance and Innovation.

Local Government Association (LGA). 2013. Improvement and Development Agency for Local Government (IDeA). London. Online: www.local.gov.uk (accessed on 15 June 2015).

Management Advisory Committee (MAC). 2010. Empowering Change: Fostering Innovation in the Australian Public Service. Canberra: Australian Public Service Commission.

Mulgan, Geoff and David Albury. 2003. Innovation in the Public Sector. London. Cabinet Office Strategy Unit. Online: www.childrencount.org/documents/ Mulgan\%20on\%20Innovation.pdf (accessed 19 May 2015).

Musgrave, Richard and Peggy Musgrave. 1980. Public Finance in Theory and Practice. 3rd edition. Tokyo: McGraw-Hill Kogakusha Ltd.

National Audit Office (NAO). 2000. Supporting Innovation: Managing Risk in Government Departments. London: Report by Comptroller and AuditorGeneral.

Podger, Andrew. 2004. 'Innovation with integrity - the public sector leadership imperative to 2020.' Australian Journal of Public Administration 63(1) (March): 11-21.

Sabel, Charles F. 2004. 'Beyond principal-agent governance: experimentalist organisations, learning and accountability'. In De Staat van de Democratie voorbij de Staat, ed. E.R. Engelen and M. Sie Dhian Ho. Amsterdam: Amsterdam University Press, 1-24.

Schumpeter, Joseph. 1942 (2014). Capitalism, Socialism and Democracy (2nd edn). Floyd, VI: Impact Books.

Senge, Peter. 1990. The Fifth Discipline: The Art and Practice of the Learning Organization. New York: Image Books. 
This text is taken from Managing Under Austerity, Delivering Under Pressure, edited by John Wanna, Hsu-Ann Lee and Sophie Yates, published 2015 by ANU Press, The Australian National University, Canberra, Australia. 